\title{
THE INTENSIFICATION OF HEAT AND MASS TRANSFER PROCESSES IN THE OPERATING CONDITION OF AUTOMATIC FIRE EXTINGUISHING SYSTEMS AT OBJECTS OF POWER
}

\author{
Olga V. Vysokomornaya ${ }^{1}$, Nikolay P. Kopylov ${ }^{1}$, Sergey Yu. Lyrschikov ${ }^{1}$, Margarita A. Dmitrienko, a \\ ${ }^{1}$ National Research Tomsk Polytechnic University, 634050 Tomsk, Russia
}

\begin{abstract}
Using the optical methods of "tracer" visualization "Particle Image Velocimetry" and "Interferometric Particle Imagine" were performed the experimental studies of the characteristics of evaporation of large single water droplets as they pass through the flames of flammable liquids - gasoline, kerosene, acetone, industrial alcohol, oil. Were determined the rates of evaporation of water under these conditions and the influence of droplet size, velocity of droplets and initial water temperature on the evaporation.
\end{abstract}

\section{Introduction}

Currently in Russia, operating more than 29 thousand objects of power, most of which are among the most fire and explosion hazard. The risk of fire at the existing power plants due to the high fire danger of technological equipment used flammable liquids and materials. On this basis, to equipping fire subdivisions of plants, as well as fire-fighting methods are of particular relevance. On this basis, to equipping fire brigades enterprises, as well as fire-fighting techniques are of particular relevance.

By type of extinguishing agent fire extinguishing system is separated into water, foam, gaseous, powder and aerosol. All of these systems have been applied in fire fighting of fuel-power complex. For example, gas fire suppression is mainly used where installed expensive electric equipment (cable installations, hardware and server rooms). Its main drawback is the toxicity of the extinguishing gas use $[1,2]$. Systems of aerosol and powder fire applied in smothering the flames in the diesel generator, cable ducts, switching racks, electrical cabinets. However, the widespread powder and aerosol extinguishing systems hampered by a number of disadvantages: weak penetrating power of powder, reduced visibility and difficulty breathing people, difficulty with cleaning at the end of extinction [3, 4]. The most widely installation of water and foam fire extinguishing. Their share in the total volume of automated fire extinguishing units exceeds $80 \%$. Foam fire extinguishing systems used in power plants for fire extinguishing in the premises of backup power engines, boilers, transformers, oil-filled reactors. Despite the fact that the foam fire extinguishing assume virtually instantaneous liquidation of a fire, they are also among the most complex. The main disadvantages of foam fire extinguishing systems are their high cost due to the additional equipment required, the complexity of the waste after the operation of the system and, as a consequence, a large, often irreparable damage to the protected

${ }^{a}$ Corresponding author: mad2@tpu.ru

This is an Open Access article distributed under the terms of the Creative Commons Attribution License 4.0, which permits unrestricted use, distribution, and reproduction in any medium, provided the original work is properly cited. 
object. In recent years, a trend can be noted quite intensive development of scientific and technological bases of technology water mist fire extinguishing [7-9]. However, the utilization parameter of physical and chemical potential of water in the suppression of the combustion is low, which results in significant expenditure of water and inability to organization of total flooding [10, 11]. This article focuses on the preparation of the fuel system and the fuel supply to the furnace of the boiler. Typically, such a system includes a fuel storage, fuel elements of the special preparation transporting device intermediate storage of fuel. Therefore, it seems appropriate to examine the process of supression of combustion of typical combustible liquids such as gasoline, kerosene, acetone, industrial alcohol and oil by the water mist suppression.

Note that to study the interaction of a large aggregate of droplets with high-temperature combustion first of all necessary to understand what are the patterns and characteristics of heat and mass transfer for a single drop.

The purpose of this work - experimental research of the evaporation of large single water droplets as it passes through the flames of typical flammable liquids (gasoline, kerosene, acetone, industrial alcohol, oil) with varying parameters of the processes (the initial size of water droplets is 2-6 $\mathrm{mm}$, the rate of water droplets is $2-4 \mathrm{~m} / \mathrm{s}$ and the initial temperature of water is $290-350 \mathrm{~K}$ ).

\section{Experimental setup and study technique}

During performance experimental studies used the same booth setup described in the article [12]. The experimental stand is a modern high-precision system of two-phase gas-, vapor-liquid streams diagnostics, working at the base of non-contact optical methods of "tracer" visualization such as "Particle Image Velocimetry" (PIV) and "Interferometric Particle Imaging" (IPI) [7-9].

Under identical initial conditions was carried out at least 10 series of experiments. The tank 7 is filled with water. The control of water temperature was carried out using chromel-copel thermocouple, which was install into a tank 7. The tank 7 connected with dosing device 9, which was arranged according to the required parameters of the water droplets. The flow of high temperature gas formed in the heat-resistant cylinder 13 (height $-1 \mathrm{~m}$, diameter $-0.3 \mathrm{~m}$ ), at the base of which installed a hollow cylinder 14 (height $-0.1 \mathrm{~m}$, inner diameters $-0.26 \mathrm{~m}$ and outer diameters $-0.3 \mathrm{~m}$ ) with combustible liquid. The temperature of the gases (combustion products) is measured using three thermocouples 15 (range of temperature measurement $0 \div 2473 \mathrm{~K}$, the error of $\pm 282 \mathrm{~K}$ ) and amounted to a range of 185-2073 K.

Then input of liquid droplets to the channel filled with high-temperature combustion products was carried out. By means of light "pulse" (from laser 2) a trajectory of droplet movement was illuminated. Procedure for video registration of droplets was carried out by a cross-correlation digital camera 3. Video images were transferred to the personal computer (PC) 4. Then, according to techniques [7-9], were determined the sizes and velocities of water droplets.

For an assessment of completeness of working liquid evaporation when droplets were moving through a flame area the integrated $\Delta R$ parameter was entered:

$$
\Delta R=\frac{R_{m}^{I N}-R_{m}^{\text {OUT }}}{R_{m}^{I N}} \cdot 100,
$$

where $\Delta R_{m}^{I N}, \Delta R_{m}^{\text {OUT }}$ - the value of average characteristic radius of liquid droplets at the inlet and outlet the cylindrical channel, $\mathrm{mm}$.

Systematic errors in gas and liquid temperature measurements did not exceed $2.5 \%$ [16], "tracer" velocities - 2\% [13, 14], droplet sizes - 1.5\% [15].Систематические ошибки измерения температуры воды и высокотемпературных газов не превышали 2,5\%, скорости - 2 \%, размеров капель $-1,5 \%$. 


\section{Results and discussion}

As a result of experimental studies were determined the main factors affecting the completeness of evaporation of water in the field of high temperature combustion products. Fig. 1 illustrates the effect of the initial size of water drops on the evaporation intensity. The experimental dependences show that with the increase of the droplet size the parameter $\Delta R$ decreases. This is due to the fact that increasing warm-up time of the surface layer to a temperature of the beginning of intensive evaporation. These conclusions can be made for all combustion products used in the experiments flammable liquids.

Another important factor affecting the completeness of the evaporation of water, is the velocity of motion drops $U_{\mathrm{d}}$. Fig. 2 shows the experimental dependencies of the parametr $\Delta R$ from the initial velocity $U_{\mathrm{d}}$ of the water droplets when moving in the flames of typical flammable liquids. Analysis of the dependencies can be concluded that when the initial velocity of the drops is increased then the parameter $\Delta R$ is decreased. This can be explain by the fact that increase the velocity of water droplets leads to a decrease the time of their movement in the high temperature region.

One more important parameter is the initial temperature of the water droplets $T_{\mathrm{w}}$. Fig. 3 shows the experimental dependencies of the parameter $\Delta R$ from the starting initial water temperature $T_{\mathrm{w}}$. From the experimental dependencies it is evident that the higher the initial temperature of the water droplets generated, the more intensive the process of evaporation.

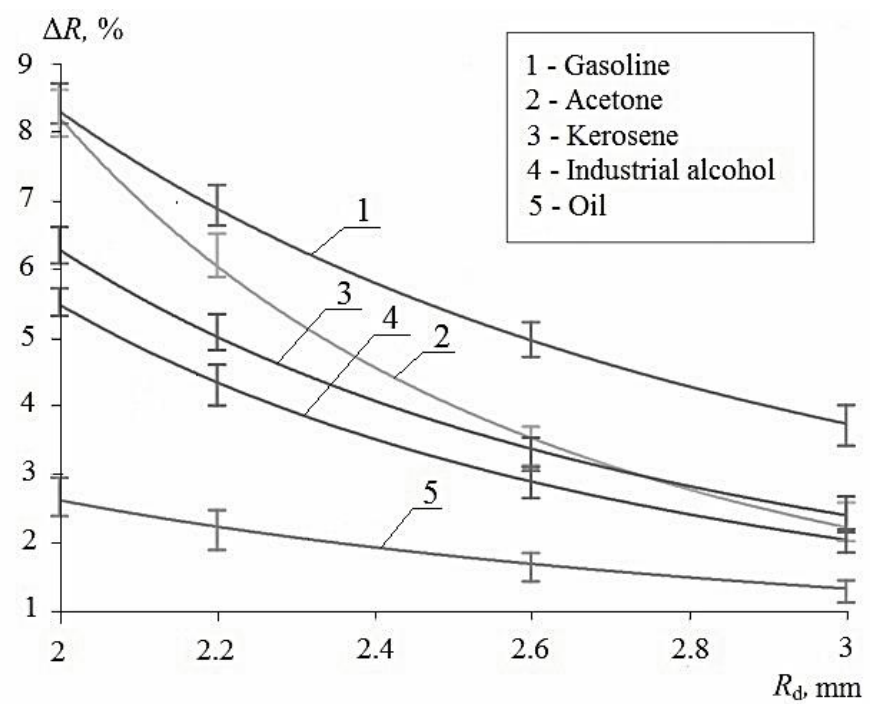

Figure 1. Experimental dependencies of the fraction of water evaporated $\Delta R$ from the initial water droplet size $R_{\mathrm{d}}$ $\left(U_{\mathrm{d}}=3.5 \mathrm{~m} / \mathrm{s}\right)$. 


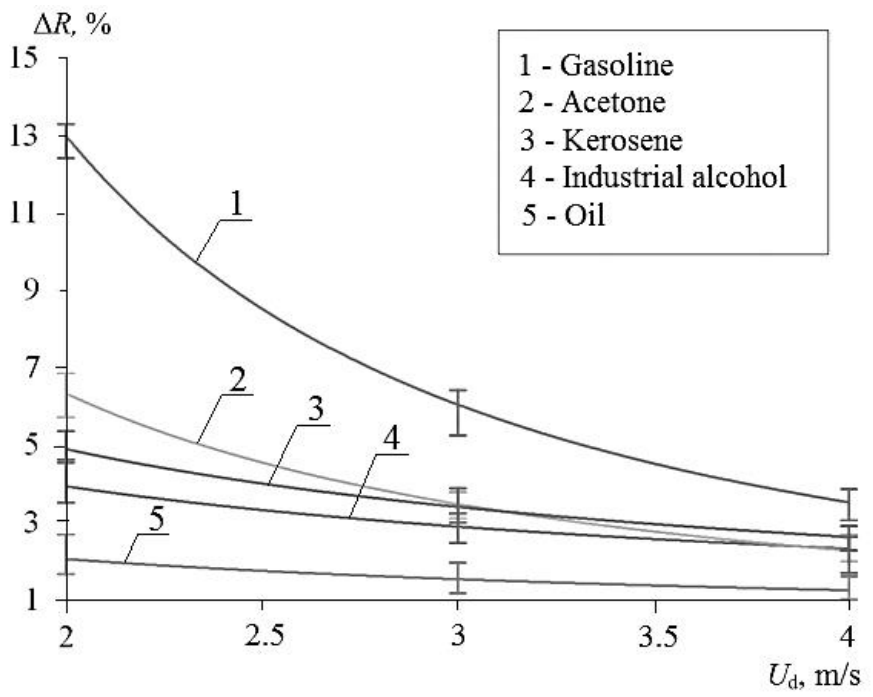

Figure 2. Experimental dependencies of the fraction of water evaporated $\Delta R$ from the initial velocity of the water droplets $U_{\mathrm{d}}\left(R_{\mathrm{d}}=2.8 \mathrm{~mm}\right)$.

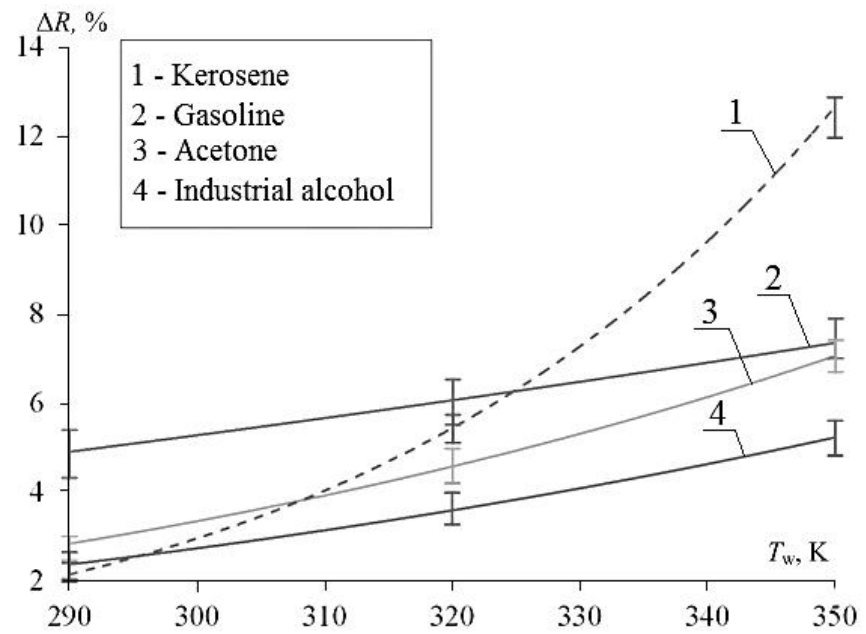

Figure 3. Experimental dependencies of the fraction of water evaporated $\Delta R$ from the starting water temperature $T_{\mathrm{w}}\left(R_{\mathrm{d}} \approx 2.7 \mathrm{~mm}\right)$.

\section{Conclusion}

Experimental study of the evaporation of large single drops of water in motion in a typical hightemperature combustion products of flammable liquids using modern optical diagnostic methods allow to analyze the patterns and characteristics of heat and mass transfer processes. Determine that a decisive influence on the completeness of evaporation of water have initial size and velocities of water droplets and their initial temperature.

The study was financially supported by the grant of Russian Science Foundation (project 14-3900003). 


\section{References}

1. Xiaomin Ni and W. K. Chow. Fire Mater., 38, 6 (2014)

2. Xiaomin Ni, Kaiqian Kuang, Xishi Wang, and Guangxuah Liao, J. Fire Sci., 28, 1 (2010)

3. Yuji Kudo, Yudai Kudo, Hiroyuki Torikai, Akihiko Ito, Fire Saf. J. 45, 2 (2010)

4. Mikhail Krasnyansky, Fire Mater., 30, 5 (2006)

5. Brian Y. Lattimer, Javier Trelles, Fire Saf. J., 42, 4 (2007)

6. S. Szönyi, A. Cambon, Fire Saf. J., 16, 5 (1990)

7. S.S. Sazhin, A.E. Elwardany, P.A. Krutitskii, V. Depredurand, G. Castanet, F. Lemoine, E.M. Sazhina, M.R. Heikal, Int. J. Therm. Sci. 50 (2011)

8. 2. A. Yu, High Temperature 51, 3 (2013)

9. O.V. Vysokomornaya, G.V. Kuznetsov, P.A. Strizhak, Heat and Mass Transfer, 86, 1 (2013)

10. Rickard Hansen, Int. J. Wildland Fire, 21, 5 (2011)

11. Jy-Cheng Chang, Chih-Ming Lin, Sheng-Lung Huang, Fire Safety Journal, 42, 4 (2007)

12. Roman S. Volkov, Olga V. Vysokomornaya, Alyona O. Zhdanova and Pavel A. Strizhak, EPJ Web of Conferences, 82, (2015)

13. R.D. Keane, R.J. Adrian, Applied Scientific Research, 49, 191 (1992)

14. J.M. Foucaut, M. Stanislas, Measurement Science and Technology, 13, 1058 (2002)

15. T. Kawaguchi, Y. Akasaka, M. Maeda, Measurement Science and Technology, 13, 308 (2002)

16. A.N. Zaydel', Simple estimates of measurement errors (Nauka Publ., Leningrad, 1968) [in Russian] 